\title{
Performance of 'Eragil' peach trees grown on different training systems
}

\author{
Alison Uberti ${ }^{*}$, Clevison Luiz Giacobbo ${ }^{1}$, Maike Lovatto $^{2}$, Adriana Lugaresi ${ }^{1}$, Jean do Prado', \\ Gian Carlos Girardi ${ }^{1}$, Alberto Ramos Luz ${ }^{3}$ \\ ${ }^{1}$ Federal University of Fronteira Sul, Rod. SC 484 km 02, Fronteira Sul, CEP 89815-899, Chapecó, SC, Brazil, ${ }^{2}$ Federal University of Rio \\ Grande do Sul, Avenida Bento Gonçalves, 7712, CEP 91540-000, Porto Alegre, RS, Brazil, ${ }^{3}$ Federal Institute of Education, Science and \\ Technology of Rio Grande do Sul, Avenida Osvaldo Aranha, 540, CEP 95700-206, Bento Gonçalves, RS, Brazil
}

\section{A B S TR A C T}

\begin{abstract}
The aim of this study was to evaluate phenology aspect, vigor, production and quality of 'Eragil' peach trees grown under different training and pruning systems. Evaluations were carried out during two seasons, 2015/16 and 2016/17. Fruit tree training and pruning systems 'Open Center' $(3.5 \times 5.0 \mathrm{~m})$, 'Ipsilon' $(1.5 \times 5.0 \mathrm{~m})$ and 'Central Leader' $(0.8 \times 5.0 \mathrm{~m})$ were used. Phenology, vegetative growth (vigor) and yield were evaluated. 'Central Leader' plants showed a higher productivity and productive efficiency. 'Open Center' plants had a greater vigor and yield per plant, however had a lower yield by unit area. Plants with ' $Y$ ' shape were intermediates between 'Open Center' and 'Central Leader' in relation of the evaluated variables. 'Central Leader' training system can be used for peach orchards in order to increase yield and productivity indexes.
\end{abstract}

Keywords: Central Leader; Phenology; Plant vigor; Planting density; Prunus persica

\section{INTRODUCTION}

Traditionally, the Open Center training system is the most used system for stone fruit tree species in Brazil. It is a low-density system, 300 to 600 peach trees per hectare (Giacobbo et al., 2003). Other training systems as the Central Leader, widespread in Europe, is practically unknown by small-scale fruit growers. This type of system is essential to adopt mechanized managements as pruning, thinning and harvesting.

According to Loreti and Massai (2006), the peach (Prunus persica) training systems can be divided into three classes when considering the tree density at orchard establishment, being low density (400 to 700 trees ha ${ }^{-1}$ ), medium density (700 to 1,000 trees ha ${ }^{-1}$ ) and high density (1,000 to 1,500 trees ha $\left.{ }^{-1}\right)$.

A peach orchard can achieve a good performance through an efficient sunlight interception (Day et al., 2005), to contribute to the photosynthesis process, fruit formation and setting, good yields and quality. According to Kumar et al. (2010), pruning management improves the plant photosynthetic efficiency, which directly influences the canopy formation and plant height. In this context pruning management is planned in order to rise the photosynthetic and yield potential of peach trees.

High planting densities and different training systems has been used in order to achieve the benefits of the maximum sunlight interception, being simpler and easier understood by managers and workers. These training systems can having a relative cost to the potential return on investment, minimizing reliance on ladders and ensuring the production of high-quality and high-value fruits (Day et al., 2005).

This research was aimed to evaluate the phenology, vigor, production and quality of 'Eragil' peach trees grown under different training systems.

\section{MATERIAL AND METHODS}

The experiment was conducted in a peach trees orchard with location of latitude $27^{\circ} 07^{\prime}$ South, longitude $52^{\circ} 42^{\prime}$ West and $605 \mathrm{~m}$ altitude above sea level. The site soil was classified 


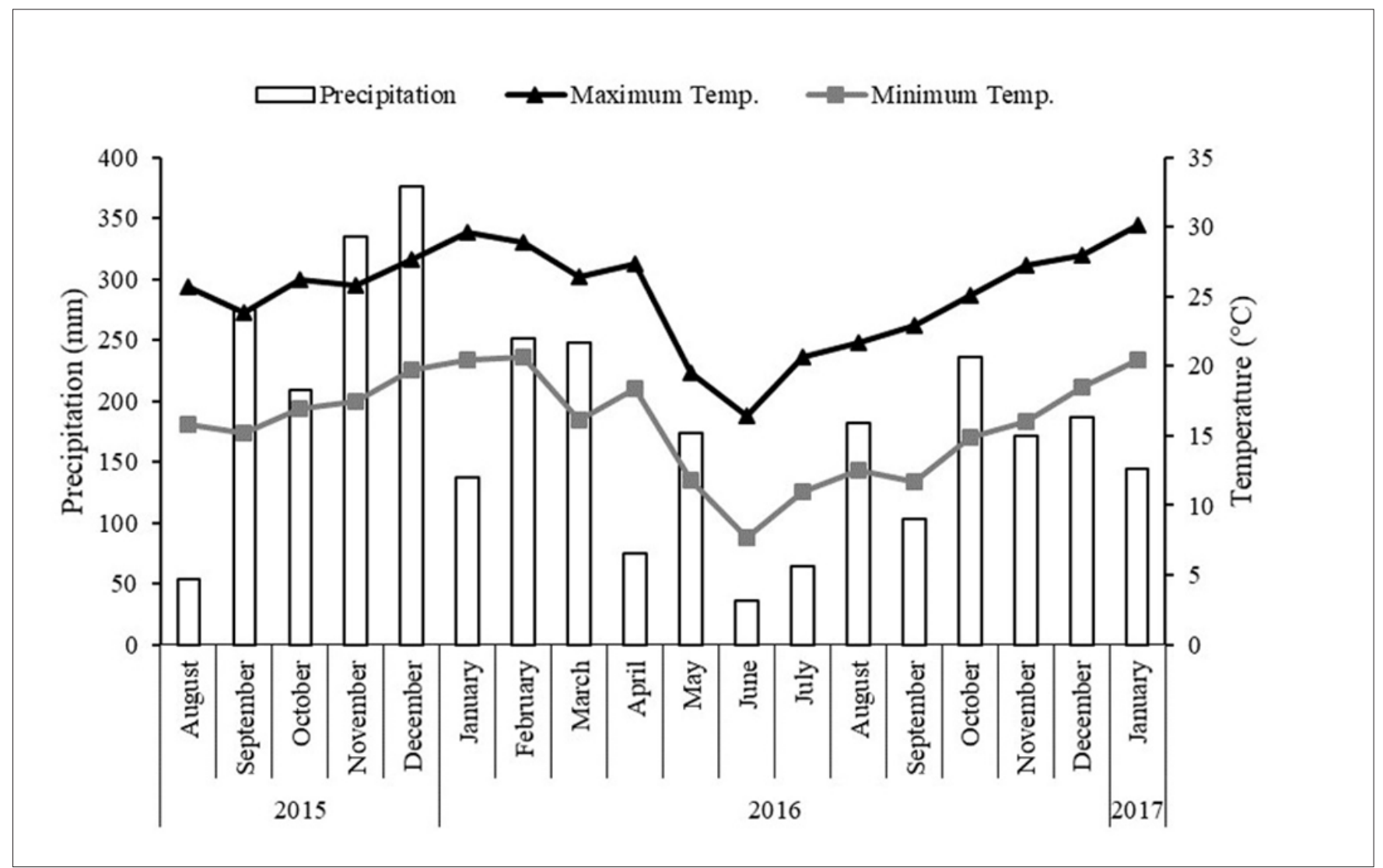

Fig 1. Temperature and precipitation conditions occurred during the trial in the site experiment. Adapted from INMET (2017).

as Dystroferric Red Latosol and Cfa climate according to Köppen. The temperature and precipitation conditions are presented in the Figure 1.

Evaluations occurred in two seasons, 2015/16 and 2016/17, in an 'Eragil' peach orchard. The 'Eragil' were grafted on Capdeboscq rootstock, from seedlings. The orchard establishment occurred in 2014 with transplanting in the north-south orientation. Treatments corresponded to the different training systems: Open Center (OC) planted at $5.0 \times 3.5 \mathrm{~m}$, Ipsilon $(\mathrm{Y})$, also known as Perpendicular $\mathrm{V}$, planted at $5.0 \times 1.5 \mathrm{~m}$ and Central Leader (CL) planted at $5.0 \times 0.8 \mathrm{~m}$. The fruit thinning was hand-performed equally in all systems.

Experimental set up was in randomized blocks design (RBD) with three replicates of five plants. Data were submitted to variance analysis by $\mathrm{F}$ test and the means compared by Tukey's HSD test at $\mathrm{P} \leq 0.05$.

Were evaluated different variables to describe the crop phenology, vegetative growth and fruit production.

a) Phenological behavior, 1) flowering (beginning of flowering, when $10 \%$ of the flowers were open; full flowering, when $50 \%$ open flowers, and; end of flowering, which $90 \%$ of the flowers did not contain petals); 2) harvest length (days).

b) Vegetative growth, 1) trunk diameter ( $\mathrm{mm})$ : measured $10 \mathrm{~cm}$ above the grafting point. 2) canopy volume $\mathrm{D}$ $\left(\mathrm{m}^{3}\right)$ : computed by $D=(L \cdot h \cdot((E 1+E 2) / 2))$ for the Y-trained trees, and by $D=$ (L.E.h) for the OC and CL-trained trees, where: $\mathrm{L}=$ canopy width in the row direction $(\mathrm{m}) ; \mathrm{E}=$ canopy width in the perpendicular row direction $(\mathrm{m}) ; \mathrm{h}=$ canopy height from the point of union of the lower branch (m); E1 = canopy thickness in the right side branch direction (m); e E2 = canopy thickness in the left side branch direction (m). 3) accumulated green mass of branches removed with pruning $\left(\mathrm{kg} \mathrm{tree}^{-1}\right)$.

c) Fruit production, 1) Fruit set rate (\%), in two selected branches were counted the flowers and the settled fruits before the thinning. 2) Number of fruits per plant. 3) Fresh fruit biomass (g), 20 fruits per tree were used. 4) Dry fruit biomass (g): it was determined in a SL-102 (SOLAB) forced air circulation oven, at $65^{\circ} \mathrm{C}$ until reaching constant weight, four fruits per plant were used. 5) Production per tree $\left(\mathrm{kg}_{\text {tree }} \mathrm{e}^{-1}\right)$. 6) Estimated productivity $\left(\mathrm{t} \mathrm{ha}^{-1}\right)$. 7) Equatorial diameter of fruit $(\mathrm{mm})$ and 8) Polar diameter of fruit ( $\mathrm{mm})$ : obtained with a digital caliper, in a random sample of 20 fruits per tree. 9) Total Soluble Solids ( ${ }^{\circ}$ Brix): a sample of 20 fruits per tree was evaluated in the equatorial region 


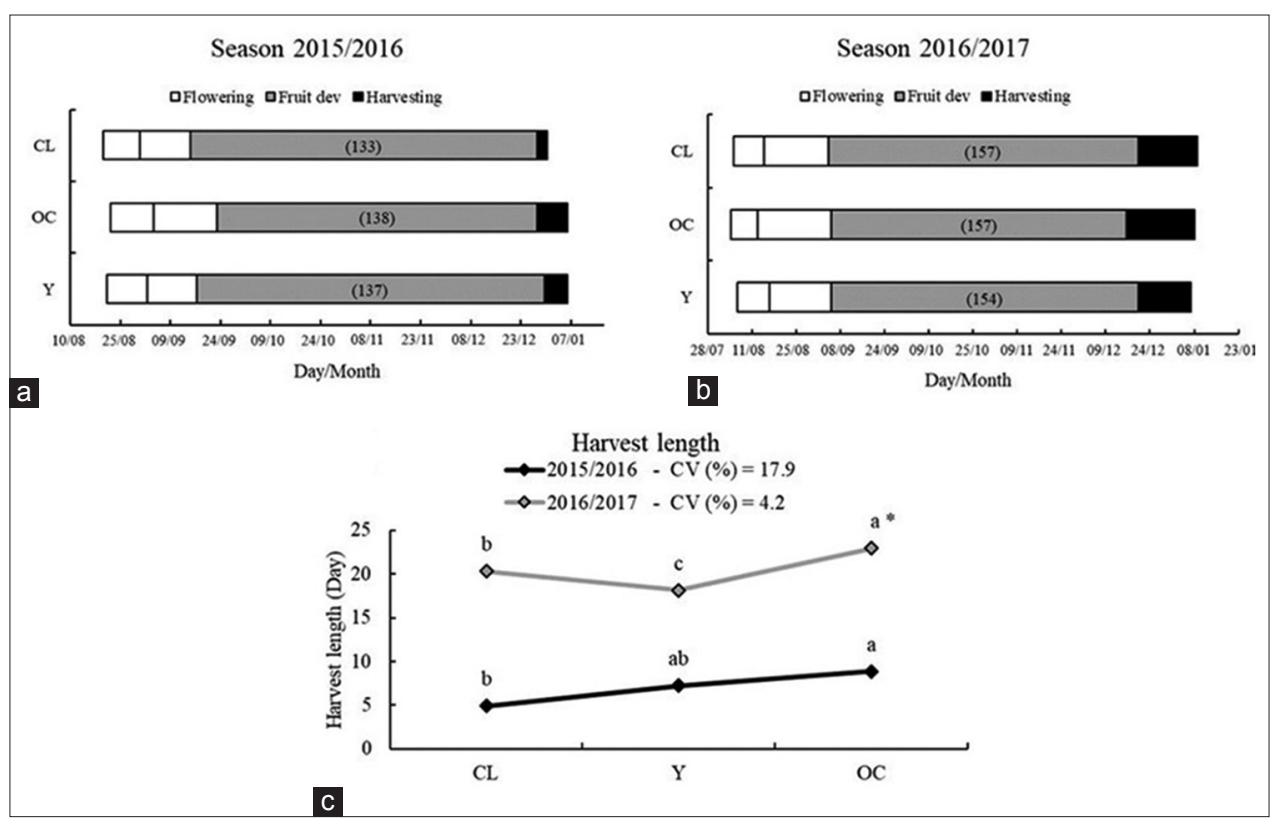

Fig 2. Phenological time from blooming to harvesting and productive behavior of 'Eragil' peach trees during the 2015/16 season (a), 2016/17 season (b) and harvest length (c). Bar dividing flowering indicates full blooming stage. "( )" represents the reproductive cycle days. Central Leader $(C L)=2,500$ tree ha ${ }_{-1}$, Ipsilon $(Y)=1,333$ tree ha-1 and Open Center $(\mathrm{OC})=571$ trees ha-1 ${ }^{-1}$ Means followed by different letters within lines are significantly different according to Tukey's test $(P \leq 0.05)$.

of the fruit, using a RTD95 (Instrutherm) bench refractometer. 10) Yield efficiency $\left(\mathrm{kg} \mathrm{cm}^{-2}\right)$ : calculated by $\mathrm{Ep}=\mathrm{P} / \mathrm{TCSA}$, where: $\mathrm{P}=$ production per tree $(\mathrm{kg}$ tree $\left.^{-1}\right) ;$ TCSA $=$ trunk cross-sectional area $\left(\mathrm{cm}^{2}\right.$ tree $\left.^{-1}\right)$.

\section{RESULTS AND DISCUSSION}

In the first season (Figure 2A), the bloom progression showed differences among training systems at the end of flowering. Central Leader (CL) and Ipsilon (Y) systems presented no differences. Open Center (OC) trained trees presented a longer flowering period, which ended seven days after the other training systems did. In 2016/17 season, the bloom progression showed no differences among training systems, where the peach trees blooming started on the first half of August and ended on the first half of September (Figure 2B).

Peach fruits ripening started earlier in the OC and CL training systems in the both studied seasons compared to the peach trees $\mathrm{Y}$ trained (Figures $2 \mathrm{~A}$ and $2 \mathrm{~B}$ ). Peach ripening was fulfillment about five days earlier on the peach trees trained in CL system than OC and Y systems in 2015/16 season, however showed no significant differences in the second studied season (Figures 2A and 2B).

The periods between blooming and ripening were similar in all the training systems evaluated, were the peach trees CL-trained completed the period in 133 days, followed by Y (137 days) and OC (138 days) systems in 2015/16 season (Figure 2A). Almeida et al. (2014) showed similar period for the 'Eragil' peach trees trained in OC system. In 2016/17 season, Y-trained trees completed the period in 154 days, while CL and OC-trained trees needed 157 days (Figure 2B).

According to Almeida et al. (2014), there were significant differences in the period between bloom and harvest among different seasons due to different weather conditions, specially related to the chilling accumulation and the time of rise temperature.

The medium and high-density planting systems (Y, CL) presented homogeneous fruit ripening, favoring the harvesting of all production in a short period of ten days. While the OC system showed heterogeneous maturation (Figure 2C).

In the second season the OC-trained trees developed a trunk diameter $46.1 \%$ higher than the CL-trained trees.

These results were similar to those obtained by Giacobbo et al. (2003), who studied "Chimarrita" peach trees conducted in different training systems, also verified differences in trunk diameter. On the other hand, Mayer et al. (2016) with the same cultivar did not obtain significant differences trees planted at different planting densities in the same training system, which makes us assume that the difference is related to the training system and not to planting density. 
Table 1: Trunk diameter, vegetative pruning mass (VPM) and canopy volume of 'Eragil' peach trees grown in different training systems during the $2015 / 16$ and $2016 / 17$ seasons

\begin{tabular}{|c|c|c|c|c|c|c|}
\hline \multirow[t]{2}{*}{ Training systems $^{(a)}$} & \multicolumn{2}{|c|}{ Trunk diameter (mm) } & \multicolumn{2}{|c|}{ VPM $\left(\mathbf{k g}\right.$ tree $\left.^{-1}\right)$} & \multicolumn{2}{|c|}{ Canopy volume $\left(\mathrm{m}^{3}\right)$} \\
\hline & $2015 / 16$ & $2016 / 17$ & $2015 / 16$ & $2016 / 17$ & $2015 / 16$ & $2016 / 17$ \\
\hline $\mathrm{CL}$ & $24.2^{\text {ns }}$ & $53.7^{\mathrm{b} *}$ & $0.6^{c^{*}}$ & $4.7^{b^{*}}$ & $0.5^{\mathrm{b} *}$ & $2.8^{\mathrm{b} *}$ \\
\hline Y & 25.2 & $68.6^{\mathrm{ab}}$ & $1.5^{\mathrm{b}}$ & $7.7^{\mathrm{b}}$ & $0.8^{b}$ & $4.8^{b}$ \\
\hline $\mathrm{OC}$ & 31.6 & $78.5^{\mathrm{a}}$ & $2.1^{\mathrm{a}}$ & $11.3^{a}$ & $2.1^{\mathrm{a}}$ & $17.5^{\mathrm{a}}$ \\
\hline CV $(\%)$ & 15.8 & 9.2 & 14.8 & 16.7 & 21.1 & 17.1 \\
\hline
\end{tabular}

(a) Central Leader $(\mathrm{CL})=2,500$ tree ha ${ }^{-1}$, Ipsilon $(\mathrm{Y})=1,333$ tree ha ${ }^{-1}$ and Open Center $(\mathrm{OC})=571$ trees ha ${ }^{-1}$. ns Not significant. * Means followed by different letters within columns are significantly different according to Tukey's test $(P \leq 0.05)$.

Table 2: Fruit set, fruit per tree, fruit mass, fruit diameter and fruit height of 'Eragil' peach trees grown in different training systems during the 2015/16 and 2016/17 season

\begin{tabular}{|c|c|c|c|c|c|c|c|c|c|c|}
\hline \multirow[t]{2}{*}{ Training systems ${ }^{(a)}$} & \multicolumn{2}{|c|}{ Fruit set (\%) } & \multicolumn{2}{|c|}{ Fruit tree $^{-1}$} & \multicolumn{2}{|c|}{ Fruit mass $(\mathrm{g})$} & \multicolumn{2}{|c|}{ Fruit equatorial diameter $(\mathrm{mm})$} & \multicolumn{2}{|c|}{ Fruit polar diameter $(\mathrm{mm})$} \\
\hline & $2015 / 16$ & $2016 / 17$ & $2015 / 16$ & $2016 / 17$ & $2015 / 16$ & $2016 / 17$ & $2015 / 16$ & $2016 / 17$ & $2015 / 16$ & $2016 / 17$ \\
\hline $\mathrm{CL}$ & $3.4 a^{*}$ & $28.0^{\text {ns }}$ & $5.3^{\mathrm{ab} *}$ & $158.8^{\mathrm{b} *}$ & $72.6^{\mathrm{a} *}$ & $91.7^{\mathrm{ns}}$ & $50.4^{\mathrm{a}^{\star}}$ & $57.0^{\text {ns }}$ & $59.0^{\mathrm{a} *}$ & $66.8^{\text {ns }}$ \\
\hline Y & $3.1^{\mathrm{a}}$ & 32.6 & $4.5^{\mathrm{b}}$ & $180.4^{b}$ & $62.5^{\mathrm{ab}}$ & 96.7 & $47.5^{\mathrm{b}}$ & 58.9 & $57.0^{\mathrm{b}}$ & 68.5 \\
\hline $\mathrm{OC}$ & $1.3^{b}$ & 31.4 & $6.0^{\mathrm{a}}$ & $331.3^{a}$ & $58.1^{\mathrm{b}}$ & 93.6 & $45.5^{\mathrm{b}}$ & 58.7 & $55.0^{\mathrm{b}}$ & 68.0 \\
\hline CV (\%) & 20.0 & 11.1 & 9.7 & 18.3 & 8.3 & 4.9 & 2.2 & 2.0 & 1.5 & 1.9 \\
\hline
\end{tabular}

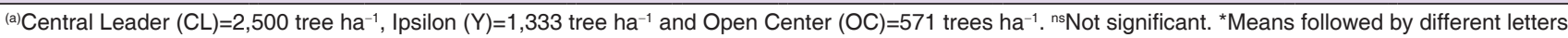
within columns are significantly different according to Tukey's test $(\mathrm{P} \leq 0.05)$.

In relation to the summer pruning, both studied seasons, that the OC-trained trees presented a larger mass of branches removed with pruning $\left(2.1\right.$ and $11.3 \mathrm{~kg}$ plant $^{-1}$, respectively). For the second season, the Y and CL-trained trees showed a reduction of $82.4 \%$ of the mass of pruned branches when compared to the OC-trained trees (Table 1).

It was observed that with the increase in planting density, it was inversely proportional to the summer pruning weight, possibly due to tree training. According to Maree (2006), the OC-trained trees should occupy the entire area available from one tree to another, so that according to Glenn et al. (2015) this system has greater interception of photosynthetically active radiation. Thus, pruning interventions are required to provide the desired shape to the plant (Kumar et al., 2010).

However, for the CL-trained trees, to leave a single dominant vertical branch (Maree, 2006), and interventions are necessary to remove branches that compete with the leader. Consequently, the amount of pruned material reduces when compared to the OC-trained trees.

The open-center peach trees had a larger canopy volume (358\%) compared to the other training systems in both seasons (Table 1). Marini et al. (1995) and Hamana et al. (2016), observed similar results, where the OC-trained trees presented larger canopy volume when compared to the trees trained in central leader.

In the first year, more fruits were observed in the peach trees trained in OC system, around $33.3 \%$ higher than the Y-trained peach trees. The peach training in CL system was intermediate. In the second year, OC-trained trees produced $95.3 \%$ more fruits than peach trees trained in the other systems (Table 2).

The number of fruits was higher in the OC-trained trees even though it presented a lower fruit set (2015/16), due to the higher canopy volume that this system presents in the first year of orchard establishment (Table 1).

Mayer et al. (2016) and Miller and Scorza (2002), described higher fruit yield in systems with lower planting density in the first year after orchard establishment. On the other hand, Marini et al. (1995), obtained higher number of fruits in the OC-trained trees, from the fourth and fifth productive season.

There was no significant difference in the total soluble solids concentration of peaches harvested in the different training systems. The average values were 9.7 and $9.3^{\circ}$ Brix in the first and second season, respectively.

In relation to the mass and size of the fruit, which corresponds to the equatorial and polar diameter (Table 2), significant differences were found in the first productive cycle. The peaches of the LC - trained trees presented greater values in mass, diameter and fruit polar diameter in relation to the fruits from trees trained in the other systems, due to the prioritization of tree structure formation in the first year in the LC system, which has a higher source/sink relation, allowing greater growth.

Mayer et al. (2016) and Pasa et al. (2017) found no significant changes in the fresh mass and size of peach fruit in the training systems used. However, Miller and Scorza (2002) found higher values in the fresh mass and fruit size 
Uberti, et al.

Table 3: Production per tree, estimated yield, cumulative yield and productive efficiency of 'Eragil' peach trees grown in different training systems during the $2015 / 16$ and $2016 / 17$ season

\begin{tabular}{|c|c|c|c|c|c|c|c|}
\hline \multirow[t]{2}{*}{ Training systems $^{(a)}$} & \multicolumn{2}{|c|}{$\begin{array}{l}\text { Production per } \\
\text { plant }\left(\mathrm{kg} \mathrm{tree}^{-1}\right)\end{array}$} & \multicolumn{2}{|c|}{$\begin{array}{l}\text { Estimated yield } \\
\qquad\left(\mathrm{t} \mathrm{ha}^{-1}\right)\end{array}$} & \multirow[t]{2}{*}{$\begin{array}{l}\text { Cumulative } \\
\text { yield }\left(\mathrm{t} \mathrm{ha}^{-1}\right)\end{array}$} & \multicolumn{2}{|c|}{$\begin{array}{c}\text { Productive } \\
\text { efficiency }\left(\mathrm{kg} \mathrm{cm}^{-2}\right)\end{array}$} \\
\hline & $2015 / 16$ & $2016 / 17$ & $2015 / 16$ & $2016 / 17$ & & $2015 / 16$ & $2016 / 17$ \\
\hline $\mathrm{CL}$ & $0.4^{\mathrm{ns}}$ & $13.0^{\mathrm{b} *}$ & $1.1^{\text {a* }}$ & $32.5^{a *}$ & $33.4^{\mathrm{a} *}$ & $0.018^{a *}$ & $0.45^{\mathrm{a} \star}$ \\
\hline $\mathrm{Y}$ & 0.4 & $17.6^{b}$ & $0.4^{\mathrm{b}}$ & $23.5^{b}$ & $23.8^{b}$ & $0.008^{b}$ & $0.35^{b}$ \\
\hline $\mathrm{OC}$ & 0.3 & $30.4^{a}$ & $0.2^{b}$ & $17.4^{c}$ & $17.5^{c}$ & $0.005^{b}$ & $0.40^{\mathrm{ab}}$ \\
\hline CV (\%) & 16.7 & 22.0 & 13.6 & 9.6 & 9.1 & 19.70 & 6.49 \\
\hline
\end{tabular}

${ }^{(a)}$ Central Leader $(C L)=2,500$ tree ha ${ }^{-1}$, Ipsilon $(Y)=1,333$ tree ha ${ }^{-1}$ and Open Center $(\mathrm{OC})=571$ trees ha ${ }^{-1}$. ns Not significant. ${ }^{*}$ Means followed by different letters within columns are significantly different according to Tukey's test $(P \leq 0.05)$.

of CL-trained trees. For these authors, the size and fresh mass of fruits have an opposite relation to the number of fruits present in the tree, that is, fruit larger size in the trees with lower number of fruits.

Dry mass found in the fruits was not influenced by the training systems $(17.8 \%$ and $15.7 \%$ in the first and second seasons, respectively).

Regarding the production per tree (Table 3), was found significant difference only for the second season (2016/17). It can be observed that in the first season on average the treatments produced about $0.4 \mathrm{~kg}$ plant ${ }^{-1}$.

For the 2016/17 season, OC-trained trees produced 98.4\% more than trees trained in LC and Y systems, which showed no significant difference between them. The low planting density of the OC-trained trees provides a higher number of productive branches, consequently reaching higher production per tree (Mayer and Pereira, 2011).

The estimated and accumulated productivity were $239.4 \%$ higher in CL-trained trees than the others training systems in the first studied year. This superiority reduced in the second year, however, still showed an estimated productivity higher in $27.7 \%$ compared to Y-trained trees and $46.6 \%$ to OC-trained trees (Table 3 ).

According to Maree (2006), CL and Y-trained trees reach good yields from the initial development of the tree, being an advantage over the OC training system. Also, orchards in high plant density reach production stability before low density orchards (Day et al., 2005).

In studies with different planting densities, Marini and Sowers (2000), and Mayer and Pereira (2011) obtained higher estimated productivity in trees planted at higher planting density in two productive seasons. Mayer et al. (2016) found the highest estimated productivity in Y-trained trees at the mean/high planting density. Giacobbo et al. (2003), obtained higher estimated productivity in CL and Y-trained trees under high planting density.
Peach trees CL-trained showed a higher productive efficiency in the first studied season (Table 3). It is observed that the production per tree was low, consequently there was no high efficiency in this season. In the second season, CL-trained trees showed a yield efficiency $28.5 \%$ higher than Y-trained trees.

High difference in productive efficiency in the two studied productive seasons, was related to the vegetative development of the trees. In the second productive season, the trees presented a greater productive capacity, which corresponds the greater quantity of productive branches and adequate structure to support the production, thus demonstrating the importance of higher density for the faster financial return to the growers.

\section{CONCLUSIONS}

Under the conditions in which this experiment was carried out, it is concluded that the 'Eragil' peach Central Leadertrained provides higher productivity and presenting earlier production, among the evaluated systems. 'Eragil' peach trees trained in Open Center showed longer harvesting time, larger canopy volume and higher yield per plant, however, lower productivity in the early years. The Y-trained 'Eragil' peaches presented as intermediates system for the evaluated variables. Fruit quality did not change among training systems.

\section{ACKNOWLEDGEMENT}

The authors wish to thank the nursery trees Frutplan Mudas Ltda for providing the peach trees.

\section{AUTHORS' CONTRIBUTIONS}

All the authors of the article had a fundamental contribution in the management of the orchard, harvesting, data collection besides writing and reviewing the final manuscript.

\section{REFERENCES}

Almeida, G. K., F. P. Magrin, P. Soldatelli and J. C. Fioravanço. 2014. Phenology and yield of peach cultivars. Rev. Ciências 
Agroveterinárias. 13: 255-265.

Day, K. R., T. M. Dejong and R. S. Johnson. 2005. Orchard-system configurations increase efficiency, improve profits in peaches and nectarines. Cal. Agric. 59: 75-79.

Giacobbo, C. L., J. L. C. Faria, O. Conto, R. F. Barcellos and F. R. C. Gomes. 2003. Behavior of the peach tree (Prunus persica L. Batsch) cv. Chimarrita in different training systems. Revs. Bras. Fruticultura. 25: 242-244.

Glenn, D. M., C. B. Bassett, T. Tworkoski, R. Scorza and S. S. Moller. 2015. Tree architecture of pillar and standard peach affect canopy transpiration and water use efficiency. Sci Hortic. 187: 30-34.

Hamana, Y., S. Sugawa, A. Hirao, K. Nakamoto, K. Shibata and H. Saneoka. 2016. Comparison of tree growth, fruit production, and labor-saving cultivation management between tree joint training system and straight line training system for peach during the first 4 years after planting. Hortic. Res. (Japan). 15: 153-159.

INMET (2017). Instituto Nacional de Meteorologia. Available from: http://www.inmet.gov.br/portal. [Last accessed on 2017 Apr 04].

Kumar, M., V. Rawat, J. M. S. Rawat and Y. K. Tomar. 2010. Effect of pruning intensity on peach yield and fruit quality. Sci Hortic. 125: 218-221.

Loreti, F., and R. Massai. 2006. State of the art on peach rootstocks and orchard systems. Acta Hortic. 713: 253-268.
Maree, W. J. 2006. Comparative Financial Efficiency of Training Systems and Rootstocks for 'Alpine' Nectarines (Prunus persica var. nectarine). (Dissertation of Master), University de Stellenbosch, South Africa.

Marini, R. P., and D. S. Sowers. 2000. Peach tree growth, yield, and profitability as influenced by tree form and tree density. HortScience. 35: 837-842.

Marini, R. P., D. S. Sowers and M. C. Marini. 1995. Tree form and heading height at planting affect peach tree yield and crop value. HortScience. 30: 1196-1201.

Mayer, N. A., T. R. Neves, C. T. Rocha and V. A. L. Silva. 2016. High planting density on 'Chimarrita' peach. Rev. Ciências Agroveterinárias. 15: 50-59.

Mayer, N. A., and F. M. Pereira. 2011. Productivity of 'Aurora-1' peach trees as affected by spacing and propagation methods of 'Okinawa' rootstock. Bragantia. 71: 372-376.

Miller, S., and R. Scorza. 2002. Training and performance of pillar, upright, and standard form peach trees-early results. Acta Hortic. 592: 391-399.

Pasa, M. S., J. C. Fachinello, J. D. Schmitz, H. F. J. Rosa J, É. Franceschi, B. Carra, M. A. Giovanaz and C. P. Silva. 2017. Early performance of 'Kampai' and 'rubimel' peach on 3 training systems. Bragantia. 76: 82-85. 